\author{
Alejandro Gabriel Lagos Peralta \\ ICEI, Universidad de Chile \\ alejandrogabriel.lagos@gmail.com \\ Hans Stange Marcus \\ ICEI/FAU, Universidad de Chile \\ hstangemarcus@yahoo.es \\ Claudio Salinas Muñoz \\ ICEI, Universidad de Chile \\ claudiorsm@u.uchile.cl
}

\title{
Fuentes no identificadas y labores accidentadas: la labor periodística como espacio para el despliegue de inestabilidad y precarización
}

\author{
Unidentified sources and rough labors: the journalistic work as \\ space for the deployment of instability and precarity
}

\begin{abstract}
Resumen
El presente trabajo problematiza, a partir de una comparación entre los resultados de los estudios de Moulian y Munizaga (2003) con los de Salinas, Stange, et al (2015, 2016, 2018a y 2018b), el rol y función de las fuentes no identificadas en la producción periodística de la prensa chilena. El ensayo describe las variables principales que constituyen la fuente periodística, señala los peligros habituales que entraña el uso de fuentes no identificadas y afirma, con base en los estudios comparados, que este tipo de fuentes no son, lamentablemente, una anomalía del sistema de prensa, sino un recurso habitual y hasta estructural del proceso de producción noticiosa, con el detrimento evidente que esto conlleva.
\end{abstract}

Palabras clave: fuentes noticiosas, fuentes no identificadas, prensa, Chile, El Mercurio, La Tercera.

\begin{abstract}
The present work problematizes -from a comparison between the results of the studies of Moulian and Munizaga (2003) with those of Salinas, Stange, et al (2015, 2016, 2018a and 2018b)-, the role and function of the sources not identified in the journalistic production of the Chilean press. This essay describes the main variables that constitute the journalistic source, points out the usual dangers involved in the use of unidentified sources and affirms, based on comparative studies, that these types of sources are, unfortunately, not an anomaly of the press system, but a regular and even structural resource of the news production process, with the obvious detriment that this entails.
\end{abstract}


Keywords: News sources, Unidentified sources, Press, Chile, El Mercurio, La Tercera.

\section{La fuente: una primera aproximación}

En el desarrollo del trabajo periodístico la fuente guarda la más alta importancia al momento de evaluar la calidad de una noticia. Por causa de esta, la construcción noticiosa puede ser tanto sólida como deficiente; su importancia es tal que puede remecer el campo informacional sólo por su procedencia. Así, por ejemplo, una hipotética acusación de malversación de fondos públicos por parte de un político de oposición: si la acusación proviene de una organización social modesta, como una junta de vecinos de algún sector periférico, su impacto será comparativamente menor que una acusación proveniente de un senador que forma parte de la misma oposición a la que pertenece el acusado: en ese caso, la situación adquiriría rápidamente eco en la red periodística. En esta clase de situaciones, la noción de status (Rodrigo, 1993) adquiere una importancia de carácter estratégico, recordándonos además, que independientemente de la naturaleza de las declaraciones, la fuente posee una escala de magnitudes de valor que excede por lejos el puro contenido periodístico.

La centralidad de la fuente en el entramado de la producción de noticias depende, sin embargo, de una gran cantidad de variables que permiten calibrar el impacto de la construcción noticiosa al momento de ser desplegada en el circuito periodístico. La magnitud de variables se puede expresar de manera sintética a través de tres grandes dimensiones: los niveles de proximidad de una fuente con los circuitos de poder, los niveles de formación de dicha fuente para con el suceso noticioso y la proximidad con el mismo. En otras palabras, es posible identificar una especie de categorización implícita al momento de seleccionar una fuente, con base en estas tres dimensiones. Dicha situación no es ajena para el reportero, incluso si la realiza de manera intuitiva. Desde ahí es posible entender lo que Gaye Tuchman (1999) denomina "ritual estratégico", ya que es desde la búsqueda de "objetividad periodística" que el reportero debe robustecer su producción noticiosa a través de diversos elementos, entre los que destaca no sólo la necesaria toma de distancia de las opiniones personales, sino también la necesidad de acercarse a las fuentes próximas a núcleos de poder o, en el caso de sucesos más mundanos, las próximas a los hechos acontecidos. (Agostini, 1985) En ese sentido, la proximidad se vuelve agente 
transversal para la construcción periodística: permite sortear los controles editoriales insertos en las dinámicas de producción noticiosa y resguardar al medio de comunicación de posibles represalias o conflictos que un determinado producto periodístico pueda arrastrar una vez publicado.

Aquí yace un importante cortafuegos que permite al periodista posicionarse desde el estandarte de la "objetividad" en el trabajo de prensa. En ese sentido, la práctica de la objetividad luce más bien como un mecanismo defensivo para el trabajador de las comunicaciones, muy por sobre las lógicas afirmativas vinculadas al mito liberal de la prensa. (Marletti, 1983)

\section{Recovecos y rostros de la fuente no revelada}

La proximidad de la fuente con el suceso periodístico o con las redes de poder que puedan estar involucradas en un determinado hecho, implica, además, la variable de la identificación de la fuente. Si el periodista logra conocer algo off the record, los manuales de ética indican que debe enfocar su esfuerzo productivo al "blanqueamiento" de dicha información, salvo casos en los que el riesgo sea muy alto. La rutina periodística, que aspira casi siempre a incorporar el reconocimiento de la fuente, admite dos grandes casos para la utilización del off the record que son "bien" soportados por los consumidores, ya que ambos atraviesan la noción de peligro. El primer caso guarda relación con el mundo del crimen.

Muchas veces una fuente del tipo "testigo presencial", al ser un vecino o un miembro de la comunidad afectada, coloca en peligro su vida al darse a conocer como fuente. En esta clase de casos, los consumidores de noticias suelen aceptar la fuente no identificada como una parte válida de la producción periodística, incorporada por lo general en el relato periodístico con frases tales como "un vecino del sector, al que por razones de seguridad no podemos dar a conocer su identidad, sostuvo...".

Esta clase de articulaciones discursivas logran incluso impregnarle una "dosis de realidad" a los relatos a través de la demostración del peligro que implica el reporteo periodístico. Un segundo caso en el que la fuente no identificada también es aceptada con relativa tranquilidad por parte de los consumidores de noticias, es cuando se trata de conflictos políticos o militares a gran escala y con gran impacto noticioso. Además del ejemplo obvio del paradigmático caso Watergate, esta clase de procedimiento se sigue ocupando para el caso de las guerras 
contemporáneas, en las que oscilan tanto los actores como los niveles de intensidad del conflicto. En esa línea, por ejemplo, el trabajo titulado Raqqa's Dirty Secret para la BBC de Londres, de los periodistas Quentin Sommerville y RiamDalati, en el que dejan al descubierto pactos de no agresión organizado por los Estados Unidos entre lo que queda del derrotado Estado Islámico y los organismos de autodefensa kurdos, muestra en toda su magnitud la fuente no identificada, primero con los testimonios extraídos de altos mandos de las fuerzas kurdas sin identificar y luego con la modificación de los nombres de algunos soldados y testigos kurdos disconformes con el acuerdo (Sommerville y Dalati, 2017). En ambos casos, la cantidad de fuentes no identificadas es matizada por las imágenes y el relato testimonial de los periodistas.

\section{Las categorías en la fuente periodística}

Si bien podemos establecer las diversas magnitudes de valor de la fuente debido a su proximidad con las redes de poder y los sucesos noticiosos, cabe destacar además, que existen otras variables que deben ser consideras al momento de su estudio, entre ellas el carácter oficialinstitucional, la expertise, la posición social y el liderazgo. Todas y cada una de ellas permiten catalogar la fuente convirtiéndola en un elemento más o menos valioso para la construcción del producto periodístico. En algunas ocasiones, es posible incluir, sobre todo en temáticas misceláneas, la novedad u originalidad de la fuente, sin embargo, en el trabajo periodístico más serio y dedicado (esto quiere decir más vinculado a problemas político-administrativos y de gestión) la prensa tiende a cubrir informaciones de interés general y, en ese sentido, son los primeros cuatro tipos de fuente más los dos tipos de proximidades (poder y suceso) las que marcan pauta al momento de la producción.

La fuente de validación oficial-institucional puede venir tanto de un ministro de gobierno como de un comunicado oficial; se aplica, además, a toda clase de instituciones que cuenten con una determinada forma de operar colectivamente frente a la sociedad. Eso quiere decir que documentos de carácter oficial-institucional pueden venir tanto de organizaciones como la Coordinadora Arauco-Malleco (CAM) como de reparticiones del gobierno de Chile.

La expertise proviene de fuentes con el estatuto de "expertos". En el caso de un atentado terrorista, un politólogo que dicta cátedra en una entidad de educación superior, autor de papers o libros sobre el asunto, puede ser considerado el experto capaz de entregar una perspectiva más 
profunda para robustecer el relato periodístico. Esta misma situación puede ocurrir con un oncólogo frente a la sospecha colectiva de que un determinado alimento detona el cáncer o un psiquiatra cuando se busca una opinión contundente frente al aumento de las tasas de suicidio en un determinado lugar. En definitiva, la expertise opera como un potente mecanismo de validación de un determinado relato periodístico.

La fuente validada por posición social no es lo mismo que la oficial-institucional. Se dice que el revolucionario mexicano Pancho Villa, ya retirado de la política en su hacienda en Canutillo, recibió al periodista Regino Hernández de El Universal. En la entrevista Villa, que estaba plenamente dedicado al reposo expresó una cierta, incluso algo tibia, simpatía por un determinado candidato a la presidencia de México. Su posicionamiento generó tal revuelo en el mundo político del México de la época, que varios expertos e historiadores sostienen que sus palabras le costaron la vida 13 meses después en el Estado de Chihuahua, camino a una fiesta familiar (Taibo II, P.,2006). La posición social no tiene sólo un vínculo con el dinero o el poder, sino que guarda relación con el impacto social proveniente de orígenes variados y diversos de una determinada fuente.

En el caso del liderazgo, la fuente queda validada por la capacidad concreta de dirigir a un determinado grupo o colectivo; en este caso, la variable del impacto social que genera dicho grupo será determinante para considerar como una fuente validada por liderazgo a su jefe o caudillo. Como última categoría, la fuente por originalidad puede ir desde el dueño del "perro que habla" hasta el youtuber derechista de moda que llama a boicotear las manifestaciones feministas: su variopinto sólo permite enmarcarla en la noción de novedad, siempre muy vinculada a las modas de la entretención inserta en las dinámicas de producción de la industria cultural (Adorno, T. \& Horkheimer, M., 1970), ocupando, por lo tanto, un espacio que excede los objetivos de análisis de la presente investigación).

Todos estos elementos anteriormente mencionados deben cumplir con ciertos estatutos instalados en la rutina periodística, entre los que destaca, salvo casos excepcionales, la identificación de la fuente y el distanciamiento en aras del registro de objetividad que deba realizar el periodista. En este marco, surgen dos elementos contradictorios y aporéticos que agreden la rutina del trabajo periodístico y que van mucho más allá de las constricciones del tiempo de entrega de la producción (deadline) o del problema de la toma de posición del 
trabajador periodístico. Apuntan más bien al circuito de producción periodística y las implicancias que este procedimiento acarrea a la multiplicidad de fuentes y a la difusión de una determinada información: nos referimos principalmente al uso indiscriminado de las fuentes no identificadas, por un lado, y a la institucionalización de la relación periodista-fuente, por otro.

\section{Tendencias entrópicas insertas en el trabajo periodístico}

Una producción noticiosa que deje satisfecha a la audiencia debe contar con ciertos "rituales estratégicos" que permitan validar el trabajo de un determinado periodista, pero además debe contar con un arsenal de cortafuegos institucionales que permitan orientar el producto en pos de una determinada línea editorial y un conjunto de procesos que le den validez al trabajo. Es en este punto que surgen ciertas tendencias entrópicas inherentes al trabajo periodístico, que socavan de manera sistemática los procesos de producción. Uno de ellos es la institucionalización de la fuente. Este proceso implica el cultivo de una relación recurrente entre un periodista y una fuente por su prestigio o cualquiera de las otras categorías mencionadas anteriormente. En este ejercicio el periodista deja de tener presente la relación conflictiva que suponen tanto intereses como favores entre un periodista y su fuente. La fuente es fundamental para la producción de la noticia, ya que permite potenciar los procesos de definición de realidad; esto la convierte en un engranaje fundamental en la cadena noticiosa, que se aproxima al periodista, sobre todo cuando se trata de conflictos de naturaleza política, con un conjunto de postulados con los cuales busca desplegar ciertas ideas fuerza que quiere estampar en la prensa. Es ahí que la cadena promotorrecolector-consumidor permite entender, aunque de manera incompleta, el rol que tienen las fuentes en las redes políticas y del poder. Este proceso, será estudiado en detalle en una próxima investigación de carácter complementario y que busca estabilizar las tendencias entrópicas inherente al trabajo periodístico. Por su parte, en el presente trabajo, nos dedicaremos a analizar en profundidad el fenómeno de la fuente no identificada, la que por su configuración objetiva, abre puertas al deterioro de la credibilidad del ejercicio periodístico frente a la audiencia.

\section{Implicancias de la fuente no identificada}

El proceso de producción noticiosa implica una delicada y conflictiva interacción con fuentes -que suelen ser a gran escala, institucionales o privadas- que, a menudo, poseen sus 
Fuentes no identificadas y labores accidentadas: la labor periodística como espacio para el despliegue de inestabilidad y precarización

Alejandro Gabriel Lagos Peralta, Hans Stange Marcus, Claudio Salinas Muñoz

propias agendas y objetivos al momento de acercarse a los periodistas para posicionar una determinada perspectiva en el circuito de prensa. Así, por ejemplo, se espera que una acción de fuerza de la CAM en la Araucanía traiga consigo una declaración de carácter institucional explicando su despliegue, lo mismo que cuando el gobierno entabla determinadas acciones de fuerza que puedan levantar una ola de cuestionamientos o inquietudes entre la población. Dado el espesor y las implicaciones que puede tener un tratamiento informacional en torno a esta clase de problemas, es que el periodista debe recurrir a su "ritual estratégico" (Tuchman, 1983) que implica, como cortafuego para estos casos, identificar y contrastar fuentes y opiniones, intentando posicionar las dos o más perspectivas en disputa. En ese sentido, los periodistas cuentan con manuales de ética y formaciones de carácter académico y profesional que desde muy temprana edad los empujan a comportarse dentro de ciertos patrones prestablecidos. Por ejemplo, si observamos el Artículo 1 del Código de Ética del Colegio de Periodistas de Chile podremos percatarnos que los ejes centrales de este dispositivo regulador recaen en la responsabilidad que tiene el periodista al momento de elaborar una noticia ${ }^{1}$. Dicha responsabilidad tiene por objeto central, preservar y potenciar la credibilidad del público sobre el trabajo del profesional de las informaciones, por lo tanto, su conservación es de carácter fundamental. Ahora, esta clase de manuales vinculados a los principios deontológicos de la profesión chocan muchas veces con las dinámicas relativas a la realidad informativa en las esferas de poder, espacios en disputa donde se suelen generar tensiones confusas, en las que identificar una fuente muchas veces se vuelve problemático. En ciertos espacios políticos o vinculados al área de defensa suelen haber trascendidos y declaraciones hechas con el previo acuerdo de que la fuente de información no sea dada a conocer. En esos casos, muchos periodistas recurren a recursos retórico-informativos tales como "Un miembro del alto mando del ejército...", "un miembro del directorio..." o "en el segundo piso del palacio de gobierno...”. En todos estos casos la fuente se vuelve inestable o, mejor dicho, inexacta. Este tipo de proceso permite que elementos y perspectivas de la agenda

\footnotetext{
${ }^{1}$ El inciso séptimo del punto uno del Código Ético del Colegio de Periodistas de Chile sostiene que "El periodista debe transparentar sus fuentes para legitimar ante la sociedad la información entregada. Sólo debe silenciarlas si éstas se lo pidieren, previa confirmación de su idoneidad y confiabilidad, respetando así la confianza otorgada al entregársele antecedentes reservados. El periodista no inventará fuentes, encubriéndolas como "un cercano", "un vocero", "un alto funcionario de la institución", etc., resguardando de este modo la credibilidad y dignidad de la profesión, tal como lo establece este Código." Es posible encontrar el código deontológico de los periodistas de Chile en el siguiente link: https://issuu.com/colegiodeperiodistasdechile/docs/nuevo_codigo_de_etica_-_xv_congreso
}

RE-PRESENTACIONES. Investigación en Comunicación 
Fuentes no identificadas y labores accidentadas: la labor periodística como espacio para el despliegue de inestabilidad y precarización

Alejandro Gabriel Lagos Peralta, Hans Stange Marcus, Claudio Salinas Muñoz

informativa del poder se posicionen sin responsabilidades adscritas en la configuración de la noticia, si bien hay ocasiones en las que el proteger la identidad de una fuente es necesario ${ }^{2}$. La expansión sistemática de esta práctica genera un doble impacto, el que por un lado permite acceder a fuentes que pueden ser más impresionantes y menos mesuradas en sus declaraciones y, por el otro, que pueden ir debilitando sistemáticamente la credibilidad del diario. El fenómeno sólo puede ser entendido de esta forma dual y, hasta cierto punto, es lógico que así sea, ya que una práctica tan reñida con los dispositivos deontológicos con los que cuenta la ritualidad estratégica del periodista sólo puede ser sopesada por una ganancia robusta en el plano informativo. Desde ahí, la masificación de la fuente no identificada hace coexistir un conjunto de fuerzas centrípetas que empujan el trabajo periodístico a límites en torno a la credibilidad, la espectacularización y el golpe informativo.

\section{Recurso peligroso reñido con la práctica}

La fuente no identificada, como mecanismo empleado por el periodista para ampliar sus accesos informacionales, tiene como ventaja elementos tales como el derecho a publicación de una información. En ese sentido, rompe el cerco del off the record y permite el acceso a espacios difíciles de llegar. Esta práctica lejana a la necesidad debido al peligro inherente de una determinada rutina periodística, le permite además ingresar a círculos exclusivos de información ${ }^{3}$. La desventaja claro está, guarda relación con el deterioro de la práctica vinculada a la obtención del recurso informativo "legítimo": al no identificar la fuente desestabiliza radicalmente el frágil juego de equivalencias entre el periodista y la misma, complicando aún más una relación generada por el mutuo interés, convirtiendo, en el peor de los casos, al periodista en una especie de relacionador público externo y funcional a un determinado organismo de poder. ${ }^{4} \mathrm{La}$

\footnotetext{
${ }^{2}$ Como en los casos del soldado raso disconforme con un trato o acuerdo militar tomado por los altos mandos con el enemigo, o el oficial institucional que avala una denuncia por abusos contra su superior.

${ }^{3}$ El cine político de la industria cultural norteamericana de los años '60 y' 70 mostró con cierta regularidad la imagen del periodista molesto para el protagonista de un determinado thriller. El periodista, nunca bien vestido y siempre husmeando por los pasillos, representa, aunque de manera peyorativa, al trabajador independiente que busca por todos los medios obtener una información decidora para completar su historia. En ese sentido, sí aparecía como un "otro poder" capaz de incidir en las perspectivas de la población en torno a una problemática coyuntural.

${ }^{4}$ Daniel Berkowitz identifica la complejidad de este fenómeno en su trabajo Reporters and their sources (2008:103). En dicho trabajo, Berkowitz reconoce que hay mucho en juego al momento del juego de presiones y equivalencias entre un reportero y su fuente: "In all, both reporters and sources have a lot to stake. Reporters put their credibility
}

RE-PRESENTACIONES. Investigación en Comunicación 
proximidad hacia estos círculo genera una especie de relación de dependencia en que, a mayor proximidad, menos puede el periodista comprometer a su fuente no identificada, situación esperable dada la compleja cadena de favores que se genera al momento de empotrarse con un conjunto de fuentes que comienzan a premiarlo por su "cooperación profesional" . Esta clase de comportamiento desestabilizador del trabajo periodístico, abre el camino hacia relatos cada vez más inestables que permiten abrir el espacio a una audiencia capaz de tolerar articulaciones ancladas en la post-verdad, ya que el deterioro sistemático de la rutina profesional -a través del uso de fuentes no identificadas que terminan por acostumbrar al lector de noticias a una estructura narrativa en el que un anónimo que le dice algo a un periodista se transforma en un recurso de verosimilitud- sólo baja los estándares del trabajo periodístico hacia niveles aún hoy insospechados. De eso a "las circunstancias en que los hechos objetivos influyen menos en la formación de la opinión pública, que los llamamientos a la emoción y a la creencia personal”, existe un paso.

\section{Registros de investigación y primeros estudios en torno al problema de la fuente no identificada}

Estudiar la naturaleza e implicancias de la utilización de la fuente no identificada en la producción periodística nacional implica detenerse necesariamente en la investigación pionera realizada entre el 21 de abril y el 21 de junio del 2003 por Diego Moulian y Giselle Munizaga. Los autores realizan un acabado estudio de medición de fuentes que abarca tres diarios de tiraje nacional, El Mercurio, La Tercera y Las Últimas Noticias, y establecen que en el lapso estudiado las fuentes no identificadas alcanzaron el $21 \%$ del total de las fuentes utilizadas en la prensa investigada, destacando La Tercera en la utilización de este cuestionado recurso, con un 27\% de fuentes no identificadas. Por su parte, El Mercurio llegó a un 18\% en la utilización de este tipo de práctica. En esa línea Munizaga y Moulian concluyen que, frente a este fenómeno, la explicación

\footnotetext{
and believability on the line with each news item they write (...) Putting both parts of this equation together suggests that the interaction between reporters and their sources is a delicately negotiated relationship (...)".

${ }^{5}$ En su estudio sobre la relación periodista-fuente en Inglaterra titulado Public relations and new sources (2003) el investigador Aeron Davis estableció que las técnicas empleadas por los relacionadores públicos han contribuido a un cierto facilitamiento de la relación entre periodista y fuente, sobre todo cuando estas últimas pertenecen a esferas de poder. Si bien Davis no aborda el problema del proceso de "domesticación" de la prensa, sí reconoce el impacto de la irrupción de los dispositivos de relaciones públicas en la esfera de la disputa comunicacional.

${ }^{6}$ Extracto de la definición de post-verdad en el diccionario de Oxford.
} 
por parte de estos medios de circulación nacional es mínima: apenas en un $2 \%$ de las notas se justifica por qué no revelaron la fuente utilizada. En esa línea, la investigación deja al descubierto lo inserta que está dicha práctica en la dinámica de producción noticiosa de los medios estudiados. Otro factor de interés y que surge en esta investigación son las cifras alcanzadas por el área política que superó la media general de un $21 \%$ alcanzando un $28 \%$ de utilización. En ese sentido, la fuente no identificada tuvo un uso sistemático en la construcción noticiosa del área política alcanzando casi un 30\% de uso, es decir, que 3 de 10 fuentes utilizadas en el área política de los medios estudiados no encuentran soporte en los manuales deontológicos de la profesión. Es ineludible considerar las lecturas que realizan los autores de la investigación en torno a este fenómeno. Por un lado surge una perspectiva que deja al descubierto los riesgos en torno a la generación de una relación espuria entre periodista y fuente; en esa hebra de razonamiento, Moulian y Munizaga agregan que la identificación de la fuente es una práctica relacionada con el "buen" periodismo. Esta práctica, según los autores, separaría al periodismo de baja calidad del periodismo de alto estándar, ya que sería capaz de separar el rumoreo ensordecedor que rodea a los medios de comunicación de alta circulación, optando por una práctica capaz de priorizar información fidedigna. (Munizaga y Moulian 2003: 10)

En este ámbito, y dejando a un lado lo valioso del aporte realizado por los investigadores de la comunicación en esta área, existe una especie de candidez argumental en torno a la idea de "deber ser" del periodista, enmarcado en el mito liberal de la prensa ${ }^{7}$, mito que opera como un fuerte aglutinador de prácticas deseables, pero que se encuentran lejos de la realidad producto de los diversos pulsos e intereses contrapuestos que dan, a lo largo del despliegue de la rutina periodística, su fisonomía final a una noticia ${ }^{8}$. Las tendencias entrópicas que se encuentran en la construcción de una noticia de circulación nacional implican para el investigador superar la

\footnotetext{
${ }^{7}$ En torno al mito liberal de la prensa, este es un horizonte transversal en muchos de los investigadores de las comunicaciones. Por ejemplo, si uno estudia el documento de Paulo Ramírez Rutinas periodísticas en los medios chilenos: una transición incompleta (2012), es posible verificar que, desconociendo las condiciones objetivas del funcionamiento de la realidad contemporánea y los núcleos de fuerza del poder, Ramírez entre sus conclusiones finales llama a la generación de un voto de confianza por parte del editor a sus periodistas, sosteniendo que "éste debe creer que su gente será capaz de captar, en los distintos sectores temáticos, aquellos hechos interesantes y actuales que constituirán las noticias". Agregando además que "este esquema necesita de un esfuerzo de imaginación y estudio mucho mayor en los reporteros".

${ }^{8}$ Le Bohec somete con particular severidad los mitos que configuran la profesión en "Les mythes professionnels des journalistes". Acá es posible vislumbrar en detalle un examen rigurosos de la configuración del "deber ser" del periodista.
} 
Fuentes no identificadas y labores accidentadas: la labor periodística como espacio para el despliegue de inestabilidad y precarización

Alejandro Gabriel Lagos Peralta, Hans Stange Marcus, Claudio Salinas Muñoz

apelación recurrente y sistemática de este mítico "deber ser" liberal de la prensa, que en la práctica ha sido más bien de carácter excepcional, y atender la cotidianeidad de la praxis periodística. Sin duda alguna, esta clase de análisis supera cualquier artillería argumental de carácter ético, enfrentándonos a motores de razonamiento desde la comunicación política que buscan establecer la importancia de la labor periodística en la generación del mapa político que configura el presente. A pesar de esto, el trabajo de los investigadores se comporta como un potente acicate que permite abrir esta clase de análisis desde soportes otorgados por una seria y potente investigación de carácter cuantitativo ${ }^{9}$.

\section{Nuevos datos levantados}

Considerando fundamentales los datos entregados por la investigación de Munizaga y Moulian, y teniendo en perspectiva el valor de dicho trabajo para la indagación en la fuente periodística, sostenemos que es relevante considerar los datos levantados por otras investigaciones, tal como es el caso de los proyectos PLU140014 y 150010 realizados por Claudio Salinas, Hans Stange, René Jara, Carlos del Valle, Constanza Yáñez y Eduardo Santa Cruz, con el objetivo de establecer un paneo primario del desarrollo y las particularidades de la rutina periodística a nivel nacional. (Salinas y Stange, 2015; Salinas, Jara, Del Valle y Stange, 2016; Salinas, Stange, Yáñez y Santa Cruz, 2018; Salinas, Stange y Santa Cruz, 2018) Estas investigaciones permiten contrastar y tensionar los datos entregados por Munizaga y Moulián y contribuir de manera general a la construcción del trabajo académico en torno a esta materia. Es necesario recalcar que las investigaciones sobre las rutinas periodísticas generadas por este equipo de académicos no tenían como objetivo exclusivo indagar en la fuente no identificada, sino que tenían por fin estratégico estabilizar la naturaleza de la fuente generada en la producción noticiosa dentro del territorio nacional. (Salinas y Stange, 2009; Faure, Salinas y Stange, 2013) Es por esto que nos hemos centrado exclusivamente en los aspectos de la investigación que

\footnotetext{
${ }^{9}$ Frente a estas concepciones "idealistas" es sugerente la definición estabilizadora empleada por Stange, Santa Cruz y Salinas sobre la estrategia periodística y sus implicancias: "Toda estrategia periodísticas es un conjunto de objetivos y definiciones ideológico-culturales, periodísticas y comerciales que, combinadas entre sí, le dan un perfil propio al medio. Se trata de definiciones y acciones prácticas que ubican a un medio de prensa dentro del contexto socio-cultural nacional, le dan una identidad y una función en el escenario de las comunicaciones y una situación dentro del mercado de la información (...) Lo importante de señalar es que, siempre, una de ellas tiende a subordinar, en algún grado, a las otras (...)”. (pág.175)
}

RE-PRESENTACIONES. Investigación en Comunicación DOI 10.35588/rp.v0i11.4089 
empalman directamente con el presente trabajo. Esos aspectos son los que apuntan i) al número de fuentes por noticia, ii) la naturaleza particular de la fuente en determinadas secciones y iii) al contraste entre los dos principales medios escritos de circulación nacional, El Mercurio y La Tercera. La búsqueda por abarcar la totalidad de aspectos de la rutina permitió extraer datos valiosos para generar una lectura profunda del comportamiento del periodista y los medios en torno a las fuentes no identificadas. Desde ahí es que consideramos que las investigaciones anteriormente mencionadas se vuelven un aporte decisivo para el presente trabajo.

La articulación metodológica desarrollada por el equipo de trabajo del que se extrajo los datos analizados, tiene como eje el estudio de la rutina periodística, esta última entendida como "una práctica discursiva e histórica" (Salinas, C. \& Stange, H., 2011: 52) y la que debe considerar como punto de partida para cualquier análisis el discurso periodístico. Su importancia radica, bien como sostienen Salinas y Stange (2011: 52) en que "el objetivo final de la rutina es la producción de un discurso, la noticia, que ha de contener rastros o marcas de las condiciones de su producción las cuales son posibles recuperar y distinguir. Este aspecto del concepto "rutina", por tanto, se expresaría metodológicamente en la pesquisa de estas huellas”. En otras palabras, esta investigación es un intento de rastrear toda materialidad generada por el proceso de producción noticioso, y en ese sentido, es plenamente pertinente para levantar un análisis que devele las pautas conductuales del periodista al momento de la generación del producto.

El proceso que tuvo por objetivo rastrear las huellas de la producción no fijó sus pautas de análisis en los contenidos, tal como lo hubiese hecho una metodología de análisis crítico de discurso (Wodak, R., 2003), por el contrario, su búsqueda marca relación con la constitución misma de la noticia, es decir, sus frecuencias, recurrencias, marcas y silencios, como bien sostienen sus autores, "como si de un campo arqueológico se tratase". (Salinas, C. \& Stange, H., 2011: 59) Este proceso permite extraer la operaciones más evidentes, tales como la relación con las fuentes y el tipo de fuentes a las que les entregan prioridad, pero además, permite establecer el grado de rutinización del proceso de reporteo y su relación con otros campos (Bourdieu, 2002) de interacción y disputa social.

En la investigación sobre la relación entre las rutinas periodísticas y la noción de pluralismo en medios nacionales y regionales de las zonas norte y sur, entre 2006 y 2015, surgen datos sugerentes en torno al trabajo y la composición de la pieza de prensa. Entre estos datos 
Fuentes no identificadas y labores accidentadas: la labor periodística como espacio para el despliegue de inestabilidad y precarización

Alejandro Gabriel Lagos Peralta, Hans Stange Marcus, Claudio Salinas Muñoz

destacan los que tomaremos y que están vinculados a El Mercurio de Santiago y La Tercera. Las fechas analizadas en ambos medios fueron la cuarta semana de agosto de 2006, la segunda semana de octubre de 2008, la primera semana de enero de 2011, la tercera semana de marzo del 2013 y la primera semana de mayo de 2015. Las fechas de la muestra son aleatorias y responden a la lógica del estudio de la rutina, en otras palabras, al estudio del periodismo de deadline. Es por eso que esta lógica de selección nos permitió no estudiar desde los hitos, sino desde la cotidianeidad del periodista de diario expresado en su producción ${ }^{10}$. Los medios seleccionados son de circulación nacional y gozan de un alto prestigio ${ }^{11}$, el que aún hoy subsiste entre la población local. En el caso de La Tercera, la muestra arrojó que el medio tiene un promedio de 2,22 fuentes por noticia. En esa línea, el mínimo de la muestra fue obtenido por las ediciones del año 2011 que generaron una media de 1,54 fuentes por noticia, cifra muy por debajo de las perspectivas desarrolladas y enseñadas en la academia, en donde se propone un mínimo de tres fuentes por pieza elaborada; por su parte, las ediciones estudiadas del año 2013 arrojaron el número de fuentes más alto de toda la muestra: 2,64 fuentes por noticia. Es necesario recordar que el diario con mayor número de fuentes no identificadas en la investigación de Munizaga y Moulián fue precisamente La Tercera. Por su parte, El Mercurio tuvo un bajo 1,79 de fuentes por noticia, experimentando un mínimo de 1,16 el año 2008 y un máximo de unas 2,52 fuentes por noticia en el año 2011. En ese sentido, no puede no asombrarnos esta clase de cifras, sobre todo porque un promedio de 1,79 no alcanza siquiera para contrastar precaria y mínimamente una información proveniente de una determinada fuente. Este último dato será tensionado en profundidad cuando levantemos las cifras vinculadas al origen de la fuente.

En el plano total de fuentes utilizadas por sección, hemos recogido los datos vinculados a las secciones «informaciones generales» ${ }^{12}$, «internacional»y «economía». Hemos escogido estas debido a que consideramos que en ellas se despliegan con mayor fuerza las dinámicas de presión entre entorno y medio, sobre todo considerando las variables que implican las problemáticas

\footnotetext{
${ }^{10}$ Este tipo de trabajo contrasta con investigaciones del tipo de búsqueda de factores a través de entrevistas como es el caso de la investigación del 2011 de Mellado y Hanitzsch titulada "What shapes the news around the world?".

${ }^{11}$ Para saber del poder que acumulan estos medios en territorio chileno, en particular, El Mercurio de Santiago, ver el sobresaliente trabajo de Claudia Lagos titulado "El diario de Agustín".

${ }^{12}$ En las investigaciones mencionadas, la categoría de «informaciones generales» engloba las informaciones de la crónica diaria, la policial y la política. Estas secciones no se diferencian claramente pues no todos los medios de la muestra las separan y era uno de los objetivos del proyecto recoger y examinar la manera en que se categorizaban los temas noticiables.
} 
político-económicas que van construyendo día a día los relatos troncales que se despliegan en los medios de comunicación. En esta línea, La Tercera tuvo 2,31 fuentes por noticia en «informaciones generales», 2,44 fuentes por noticia en «internacional» y 2,32 fuentes por noticia en «economía», todas por sobre el promedio general (2,22 fuentes por noticia) pero bajo el "mínimo deontológico" (tres fuentes por noticia). En el otro lado del espectro, El Mercurio de Santiago marcó 1,88 fuentes por noticia en «informaciones generales», 2,18 fuentes por noticia en «internacional» y un escueto 1,66 fuentes por noticia en «economía». En esta última sección, El Mercurio está por debajo de las 1,79 fuentes por noticia en el marco general, cifra que ya era inusualmente baja para un medio que alega antigüedad, excelencia en el trabajo informativo y profesionalismo en el tratamiento de las fuentes.

Frente a los datos vinculados a la presencia de un determinado tipo de fuente por medio, la existencia de las fuentes entendidas como «documento», estabilizado por la investigación como trabajos equivalentes a informes y encuestas, literatura técnica y documentos oficiales o institucionales, presentaron resultados similares en ambos medios. En el caso de La Tercera los documentos abarcaron un $13,1 \%$ del total de las fuentes empleadas durante la muestra, mientras que El Mercurio alcanzó un 14,6\% del total. Esto nos arroja datos relevantes sobre la influencia y los márgenes de acción de ciertos centros de investigación que cada cierto tiempo despliegan informes y datos para los medios de comunicación de circulación nacional.

Entre los datos más relevantes y decidores nos encontramos con los relativos a la presencia de la reproducción de comunicados y conferencias de prensa. Frente a este tipo de fuentes la muestra de La Tercera marcó un 49,5\% del total de fuentes desplegadas a lo largo del producto impreso; por su parte, El Mercurio de Santiago llegó a un 42,1\%, el que si bien es más bajo que el porcentaje arrojado por el diario de Copesa, no deja de manifestar que casi la mitad del rastreo de fuentes que realizan los periodistas consiste en asistir a espacios pre-fabricados por instituciones y centros de poder para desplegar sus posicionamientos frente a la opinión pública. Sin duda, este punto es particularmente inquietante y requiere una profundización más allá de cualquier apelación al mito liberal de la prensa.

En el área de los trascendidos, es decir de las fuentes no identificadas, la muestra arrojó una cifra inferior a la de Moulian y Munizaga, ya que si entre Las Últimas Noticias (un tabloide matutino publicado por la empresa El Mercurio), El Mercurio y La Tercera, las fuentes no 
identificadas arrojaron en la investigación del 2003 un total de un 21\%, alcanzando en $E l$ Mercurio un 18\% y en La Tercera un escandaloso 27\%, por su parte, en nuestras investigaciones hubo un 10,2\% de trascendidos en La Tercera y un 9\% en el caso de El Mercurio. Si bien la cifra es sustantivamente más pequeña, deja igualmente de manifiesto que el trascendido es un recurso sistemático por parte de los medios de circulación nacional y que frente a su despliegue hay nulas explicaciones sobre su uso. Acerca de este tema en particular, nos haremos cargo en las conclusiones del presente trabajo.

\section{Tipo de fuente por secciones del medio estudiado}

Un aspecto central es establecer cifras generales que nos permitan comprender los flujos de comportamiento de la rutina periodística de los medios estudiados, aunque eso no alcanza para comprender los movimientos estratégicos y los flujos de poder en la configuración de la noticia. Por ejemplo, no tiene la misma relevancia un trascendido vinculado al conflicto en la Araucanía que el generado por un supuesto romance oculto de un futbolista seleccionado nacional. En ese sentido, y con el objetivo de estabilizar las líneas de interés del presente trabajo, es que desplegamos la presencia de documentos, comunicados y conferencias de prensa, además de los trascendidos en las secciones «informaciones generales», «internacional» y «economía». Siguiendo esa línea de trabajo, la presencia de comunicados y conferencias de prensa en $\mathrm{La}$ Tercera fueron $64,2 \%$ en «informaciones generales», 56,1\% en «internacional» y 45,6\% en «economía»; por su parte en El Mercurio, las cifras se expresaron como un 53,1\% en «informaciones generales», 54,8\% en «internacional» y un 33,7\% en «economía». Si bien las cifras de ambos medios son relativamente altas, salvo en la sección de economía de El Mercurio, La Tercera deja de manifiesto una dependencia a este tipo de fuente en términos generales y en sectores estratégicos en torno a la configuración de la opinión pública.

Frente a los documentos como fuente generadora de información, La Tercera tuvo en «informaciones generales» un 16,6\%, en «internacional» un 12,8\% y en «economía» un 23,7\%. Desde el otro lado, El Mercurio tuvo en la sección de «informaciones generales» un 16,5\%, en «internacional» un $13,4 \%$ y en «economía» un $21,5 \%$. En ambos medios es posible observar un aumento en la presencia de documentos al momento de generar un contenido de carácter económico, además de poseer cifras equivalentes en cada sección analizada. 
Fuentes no identificadas y labores accidentadas: la labor periodística como espacio para el despliegue de inestabilidad y precarización

Alejandro Gabriel Lagos Peralta, Hans Stange Marcus, Claudio Salinas Muñoz

Los trascendidos en La Tercera fueron un 9,2\% en «informaciones generales», un 8,8\% en «internacional» y un 12,6\% en la sección económica, por su parte, El Mercurio tuvo un 8,5\% de trascendidos en «informaciones generales», un $11,3 \%$ en «internacional» y un $8,9 \%$ en «economía». Estas cifras revelan que, si bien los trascendidos muchas veces no alcanzaron los dos dígitos en las secciones estratégicas, están lejos de ser cifras marginales que alcancen el 3\% o 5\%; por el contrario, las datos levantados por el equipo de los proyectos PLU140014 y PLU150010 dejan de manifiesto que el trascendido está inserto dentro de las rutinas periodísticas actuales y que han estado presentes a lo largo de lo que va el siglo XXI.

\section{A modo de conclusión: tensiones, rutinas periodísticas y fuerzas entrópicas}

La realización de un trabajo periodístico en un periodo marcado por la irrupción permanente de nuevas tecnologías y el impacto sostenido de redes informacionales -que permiten difuminar en los cuerpos sociales nociones y relatos muchas veces amparados en troncos argumentales emotivos, conspirativos y/o francamente delirantes- no es tarea fácil. Muy por el contrario, el rol del periodista hoy se vuelve cada vez más accidentado, tanto por el aumento de la fuerza de los relatos corporativos ${ }^{13}$ a través de los dispositivos cada vez más afinados de relaciones públicas, como por la generación explosiva de una competencia argumental que muchas veces no responde a ningún estándar ${ }^{14}$. Sin embargo, los principales agresores del trabajo periodístico contemporáneo han sido a todas luces las fuerzas entrópicas presentes en la labor de prensa misma y su inextricable vínculo con el poder. El periodista que husmeaba y publicaba sendos golpes de cátedra que hacían retroceder la corrupción y las malas prácticas -construido por décadas de relatos presentes en la industria cultural y que sólo podemos entender como una exacerbación del mito liberal de la prensa- ha dado paso a un periodista más fiel a la conferencia de prensa marcada por la presencia masiva de grabadoras y estudiantes en práctica. En ese

\footnotetext{
${ }^{13}$ Estos relatos desplegados en un dispositivo mediático en el que la bioeconomía ha tomado un papel cada vez más relevante, refleja los nuevos juegos de poder expresados en la irrupción de nuevas subjetividades y un nuevo modo de producción, en el que el influir y masificar determinadas nociones estratégicas para una determinada corporación se vuelve clave para la sobrevivencia de la misma. Estas formas del hacer la política y la información son mencionadas y abordadas en el trabajo del investigador Carlos Ossa titulado "El ego explotado".

${ }^{14}$ La investigación de Myriam Redondo titulada "Pasividad y permisividad en red" sobre los estándares de calidad en el periodismo web y en la que hace mención al "copypasteo" y a la difuminación de los relatos generados por los dispositivios corporativos de relaciones públicas, grafican que mucho a lo que hacemos referencia y se grafica en nuestra investigación, es una tendencia que está lejos de ser puramente local.
} 
espacio, la precarización laboral sufrida sistemática y sostenidamente por el periodista ha generado un sujeto "sobreviviente" al que no le vale la pena discutir con editores la publicación de tal o cual información en el medio para el que trabaja. La baja presencia de fuentes -las que siempre han servido para resguardar el ritual estratégico y, con ello, el prestigio del oficio- no es otra cosa que el reflejo de un trabajador de la información que tiene poco tiempo para realizar una labor de calidad y que, frente a la ingente información que le entregan los canales oficiales, suele articular un relato medianamente coherente que en última instancia le da rendimiento. Por su parte, la presencia de la fuente no identificada como arsenal permanente en la construcción noticiosa demuestra la fractura que existe actualmente entre los organismos de prensa y los manuales que prescriben sus procedimientos "ideales". La razón de esta presencia persistente de las fuentes no identificadas en los productos periodísticos debe ser motivo de discusión y reflexión en los centros de pensamiento de las comunicaciones, al igual que la concentración de los medios de comunicación en territorio chileno y la realidad salarial de los trabajadores de la información, situación que se refleja en la necesidad latente de los investigadores de la prensa de estudiar necesariamente los medios vinculados a Copesa y a El Mercurio. En ese sentido, esta síntesis de una investigación mayor, como fueron los PLU140014 y PLU150010 nos empuja más allá de la pura constatación de que existe un déficit de fuentes en los medios escritos más prestigiosos del país, y que estos utilizan las fuentes no identificadas como parte de su repertorio de manera regular y sostenida, llevándonos al complejo camino que implica establecer ciertos mínimos comunes que permitan pensar un aumento de la calidad de la prensa local, observando necesariamente la cantidad mínima de personal con el que debe contar cada medio, los métodos de financiamiento y el rol del Estado como garante de la preservación de la libertad de expresión, así como la vinculación entre los organismos deontológicos del quehacer periodístico y los diversos medios de comunicación. Para finalizar cabe sostener que todo este trabajo debe hacerse en el marco de un funcionamiento y una regularidad en la producción periodística que no se posicione desde el mito liberal de la prensa, sino desde una concepción realista en la que la calidad mínima de la producción se eleve bajo estándares de verosimilitud construidos entre la opinión pública y los organismos de prensa. En ese sentido, no existe mejor agente revitalizador de la práctica periodística que una población cargada de politicidad y cuestionamientos, que 
empuje a los medios a estabilizar su rol para con su entorno. En este espacio, el mito ha de abrir paso a la sobrevivencia del medio.

\section{Bibliografía}

Adorno, T. \& Horkheimer, M. (1970). Dialéctica del Iluminismo. Buenos Aires: Sur

Berlowitz, D. (2008). "Reporters and their sources". En The handbook of journalism studies (102-115). Nueva York: Routledge.

Bourdieu, P. (2002). Campo de poder, campo intelectual. Itinerario de un concepto. Buenos Aires: Montressor.

Davis, A. (2003). "Public relations and news sources". En News, public relations and power (2742). Londres: Sage.

Faure, A., Salinas, C., \& Stange, H. (2013). "The Dominance of Common Sense. The Influence of the Media System on Professional Practices of Journalists in Chile, 1970-2000". Media Structures and Media Performance: State of and Perspectives for Communication Research. Puppis, M., Künzler, M. \& Jarren, O. (eds). Zurich: IPMZ (Series "Relation") (283-301).

Hanitzsch, T., \& Mellado, C. (2011). "What Shapes the News around the World? How Journalists in Eighteen Countries Perceive Influences on Their Work". International Journal of Press/Politics, 16 (3), 404-426.

Lagos, C. (ed.). (2009). El diario de Agustín: Cinco estudios de casos sobre El Mercurio y los derechos humanos (1973-1990). Santiago de Chile: LOM Ediciones.

Le Bohec, J. (2000). Les mythes professionnels des journalistes. L'état des lieux en France. Paris: L'Harmattan, coll. Communication et civilization.

Marletti, C. (1983). "Falsi giornalistici e costruzione dela realtá", Problemi dell'informazione, año VIII, n.2.

Moulian, D. y G. Munizaga (2003). Las fuentes bajo sospecha. Los riesgos del uso de trascendidos y de fuentes no identificadas. [reporte de investigación] Santiago: FUCATEL. http://www.observatoriofucatel.cl/wpcontent/uploads/2008/11/investigacion-senor-fuente.pdf 
Alejandro Gabriel Lagos Peralta, Hans Stange Marcus, Claudio Salinas Muñoz

Ossa, C. (2016). El ego explotado. Capitalismo cognitivo y precarización de la creatividad. Santiago: Departamento de Artes Visuales

Ramirez, P. (2012). "Rutinas periodísticas en los medios chilenos: una transición incompleta". Cuadernos.Info, (10), 22- 33. https://doi.org/10.7764/cdi.10.229

Redondo, M. (2007). "Pasividad y permisividad en Red. Internet y las "nuevas" estrategias de contacto con las fuentes informativas”. Comunicación y sociedad, (20), 87-101.

Rodrigo, M. (2005). La construcción de la noticia. Barcelona: Paidós

Sommerville, Q. \& Dalati, R. (2017). Raqqa's dirty secret. Noviembre 13, 2017, de BBC Sitio web: https://www.bbc.co.uk/news/resources/idt-sh/raqqas dirty secret

Salinas, C., \& Stange, H. (2009). Rutinas periodísticas. Discusión y trayectos teóricos sobre el concepto y su estudio en la prensa chilena. Santiago: Universidad de Chile, col. ICEI Cuadernos, 5.

Salinas, C., \& Stange, H. (2011). “Aproximaciones metodológicas a las prácticas profesionales de los periodistas". En Sujetos y actores sociales: reflexiones en el Chile de hoy (43-65). Santiago: LOM.

Salinas, C., \& Stange, H. (2015). "Burocratización de las rutinas profesionales de los periodistas en Chile (1975-2005)". Cuadernos.info, (37), 121-135.

Salinas, C., Stange, H., Jara, R., \& Del Valle, C. (2015). "Los desafíos de la integración y el pluralismo: La prensa nacional y regional en Chile". Chasqui, (130), 313-328.

Salinas, C., Stange, H., Santa Cruz, E., \& Yáñez, C. (en prensa). "Pluralismo informativo y burocratización del trabajo periodístico en dos contextos de prensa diaria”. Estudios del Mensaje Periodístico, 24 (2).

Stange, H. \& Salinas, C. \& Santa Cruz, E. (2018). "Prensa y sociedad. Estrategias y modelos periodísticos en el Chile neoliberal". En Transformaciones de la esfera pública en el Chile neoliberal (169-192). Santiago: Ril.

Taibo II, P. (2206). Pancho villa, una biografía narrativa. Madrid: Planeta

Tuchman, G. (1999). "La objetividad como ritual estratégico: un análisis de las nociones de objetividad de los periodistas”. Cuadernos de información y comunicación, (4), 199218.

Tuchman, G. (1983). La producción de la noticia. México D.F.: G. Gili S.A. 
Fuentes no identificadas y labores accidentadas: la labor periodística como espacio para el despliegue de inestabilidad y precarización

Alejandro Gabriel Lagos Peralta, Hans Stange Marcus, Claudio Salinas Muñoz

Wodak, R. (2003). "El enfoque histórico del discurso". Métodos de análisis críticos del discurso, Wodak, R. \& Meyer, M. (eds). Gedisa: Barcelona (101-142). 